\title{
Environmental Sustainability By Recycling of PET Plastic Bottles And Reusing Them In Textile Industry: A Game-Theoretic Approach
}

Hamed Jafari ( $\nabla$ hamed.jafari@iut.ac.ir)

Isfahan University of Technology https://orcid.org/0000-0002-9352-887X

\section{Research Article}

Keywords: Sustainability, Sustainable supply chain, Recycling, Recycling of PET plastic bottles, Green production, Game theory

Posted Date: July 6th, 2021

DOI: https://doi.org/10.21203/rs.3.rs-664190/v1

License: (a) (i) This work is licensed under a Creative Commons Attribution 4.0 International License.

Read Full License 


\title{
Environmental sustainability by recycling of PET plastic bottles and reusing them in textile industry:
} A game-theoretic approach

\author{
Hamed Jafari \\ Corresponding author, Assistant Professor, Department of Industrial Engineering, Golpayegan Campus, \\ Isfahan University of Technology, Isfahan, Iran
}

E-mail: hamed.jafari@iut.ac.ir

Phone: (+9831) 5724-3238; Fax: (+9831) 5724-0067

\begin{abstract}
This study considers a sustainable supply chain including the collector, cleaner, and recycler for recycling of PET plastic bottles and reusing them in textile industry. In the market, some suppliers of textile industry purchase cleaned and non-fragmented bottles and then they fragment them, whereas others prefer to buy recycled materials (i.e., cleaned and fragmented bottles). The collector collects used plastic bottles. To meet demand of the recycled materials, the collector transfers a portion of the collected bottles to the recycler and then the recycler cleans and fragments them. Furthermore, the collector cleans another portion of the collected bottles himself or via a cleaner to meet demand of the cleaned and non-fragmented bottles. In this setting, two different structures are established for transferring the cleaned bottles to suppliers. Under the first structure, the collector cleans the collected bottles through the cleaner by giving a share of the profit to him, while he is equipped with the bottles cleaning technology by paying a setup cost under the second structure. Moreover, the game-theoretic models are developed including Nash, Stackelberg, and Centralized to make decisions under two considered structures.
\end{abstract}

Keywords: Sustainability; Sustainable supply chain; Recycling; Recycling of PET plastic bottles; Green production; Game theory.

\section{Introduction}

In the last two decades, by increasing natural resource scarceness, the plastic waste is taken into consideration as a resource that should be globally managed (Akbar and Liew 2020). It has been reported that about $50 \%$ of the plastic waste is recyclable and can be reused in different industries (Goli et al. 2020). Recycling is an efficient approach to improve the plastic waste management (Caetano et al. 2020; Zgheib and Takache 2021). As a matter of fact, burning the plastic waste emits dangerous chemicals to the environment and this leads to increasing carbon emission (Eneh and Policy 2021). Therefore, recycling of the plastic waste avoids toxic pollution as well as saves natural resources (Menges et al. 2021). In this point of view, manufacturing using these recyclables rather than the virgin materials makes the environment friendlier (Gautam and Kumar 2005; Van Caneghem et al. 2019).

PET plastic bottles (bottles made of polyethylene terephthalate) are taken into account as a considerable portion of the plastic waste (Mohanraj et al. 2017). Reports indicate that approximately $86 \%$ of PET plastic bottles used in the United States are dumped in the landfills (Minakova et al. 2018). Moreover, up to 450 years are taken for the plastic bottles to decompose (Kreiger et al. 2012; Ros-Chumillas et al. 2007). Thus, it seems that recycling of PET plastic bottles has a significant role to make the environment friendlier.

By increasing the petroleum prices, recycling of PET plastic bottles leads to higher profits for the manufacturers compared with the situation in which they use the virgin materials (Jacobs and Subramanian 2012). In fact, due to the environmental effects, recycling of the plastic bottles for reusing them in different industries has attracted a considerable attention in recent years (Doan et al. 2020; Gopinath et al. 2020). As an example, PET plastic bottles can be collected, cleaned, and recycled to be reused in textile industry (Majumdar et al. 2020). They are considerably used to produce garments. Green clothing concept refers to fabrics made from the sustainable materials like plastic and bamboo (Leonas 2017; Shirvanimoghaddam et al. 2020). Nowadays, many people wear the green garments produced from the used plastic bottles (Casadesus-Masanell et al. 2009). In fact, buying the green garments is as a sign of the responsibility to sustain the environment. Thus, it can be stated that recycling of PET plastic bottles and reusing them in textile industry leads to a significant decrease in carbon emission and raw materials consumption (Kumar et al. 2020; Rausch and Kopplin 2020).

Game theory investigates the competitive and cooperative behaviours on different situations (Lou et al. 2004; Yu et al. 2020; Zhou et al. 2019). Many studies have discussed how to make decisions using the gametheoretic framework in various supply chain structures. Recently, applications of the game-theoretic approach have greatly increased in the sustainable supply chain management. Nevertheless, to our knowledge, few studies on the waste recycling issue have applied the game-theoretic approach to make decisions under the considered supply chain. Most of these studies are addressed as follows: 
He and Yuan (2020) studied the waste recycling issue by considering the consumers' quality perceptions of the recycled materials. Krikke et al. (2003) and Chen and Sheu (2009) investigated the recyclability rate of a product applying the game theory. Lu et al. (2014) developed a cooperative game theory model for analyzing the operations efficiency in a recycling industry. Jin et al. (2020) proposed a game-theoretic model to recycle the plastic waste in industrial parks and revealed some standards for the waste recycling. Qiu and Huang (2007) studied the recycling issue on a closed-loop supply chain under the stochastic demands. Grimes-Casey et al. (2007) applied the game theory to specify the lifecycle of the bottle packaging and present a framework to select between the disposable and refillable bottles. Xu et al. (2020) explored a decision-making mechanism to determine the prices and collection rate under a closed-loop supply chain. Moreover, Kaushal and Nema (2013), Kaushal and Nema (2012), and Kaushal et al. (2015) used the game theory to make decisions related to management of the electronic waste.

Sheu (2011) and Sheu and Chen (2012) established a three-stage game-theoretic model between a supplier and a manufacturer who produces a recyclable product. Jafari et al. (2017) considered a three-echelon supply chain including a collector, a recycler, and a manufacturer to procure a new product from the recyclable materials.

Yi et al. (2014), Feng et al. (2017), and Fu et al. (2012) studied the issue of the channel selection on the closed-loop supply chain. Furthermore, Huang et al. (2013) established a closed-loop supply chain with dual recycling channels. In this structure, products are sold via a retailer in the forward supply chain, whereas the retailer and a third party collect the used products in the reverse supply chain.

Long et al. (2020), Ma et al. (2020), and Chen and $\mathrm{Hu}$ (2018) investigated the manufacturing and recycling processes on the green development performance using an evolutionary game model. Su (2020), Ji et al. (2015), and Soltani et al. (2016) established an evolutionary game model among three stakeholders including the government agency, waste recycler, and waste producer. Moreover, Shen et al. (2018) proposed an evolutionary game consisting of the contractors and some manufacturers of the construction materials based on the prospect concept of the behavioral economics.

The current study discusses recycling of PET plastic bottles under a sustainable supply chain including the collector, cleaner, and recycler. PET plastic bottles are collected, cleaned, and fragmented to be reused in textile industry. Some suppliers of textile industry buy the cleaned and non-fragmented bottles and then they fragment them, while others prefer to purchase the recycled materials (i.e., the cleaned and fragmented bottles). Under the considered supply chain, the used plastic bottles are collected by the collector. A portion of these collected bottles is transferred to the recycler and then he cleans and fragments them and another portion meets the suppliers' demand for the cleaned bottles through the collector or cleaner. In this point of view, two different structures can be established for transferring the cleaned bottles to suppliers. Under the first structure, the collected bottles are cleaned via the cleaner giving a share of the profit by the collector to him, whereas the collector setups the bottles cleaning technology himself by paying a fixed cost under the second structure. Moreover, the game-theoretic approach is applied to make the decisions under various behaviors established among the members.

In summary, in this study, efforts are done to answer to the following research questions:

Research Question 1. Under the various interactions established among the members, what are the value of the decisions made by them?

Research Question 2. Under the various interactions among the members, which of the following structures is more beneficial from the collector's point of view?

Cleaning the collected bottles via a cleaner by giving a share of the profit to him.

- Establishing the bottles cleaning technology by paying a setup cost.

Research Question 3. How the decisions are affected by developing different game-theoretic models?

Research Question 4. How the decisions are changed by implementing a sensitivity analysis?

Hence, it can be stated that the major characteristics that distinguish this study from those found in the literature are:

(1) In this study, a novel sustainable supply chain structure is established to collect, clean, and fragment PET plastic bottles and reuse them in textile industry.

(2) The study is the first one that analyzes the collector's decision about whether to clean the collected bottles through a cleaner giving a share of the profit to him or to establish the bottles cleaning technology himself by paying a setup cost.

The rest of the paper is organized as follows: Section 2 provides a detailed description of the research problem. In Section 3, the game-theoretic models are developed and the equilibrium strategies are obtained under the various interactions among the members. Section 4 deals with the results and a discussion of the equilibrium decisions given by the games. Moreover, conclusions and directions for future studies are included in Section 5. 


\section{Problem description}

In this study, recycling of PET plastic bottles and reusing them in textile industry is discussed. PET plastic bottles can be collected, cleaned, and fragmented to be reused in textile industry as appropriate substitutable for virgin materials. In the market, some suppliers of textile industry procure the cleaned and non-fragmented bottles and afterward fragment them themselves, while others prefer to buy the recycled materials (i.e., the cleaned and fragmented bottles). As a matter of fact, some suppliers able to fragment the cleaned bottles themselves and others are not equipped with this technology and have to purchase the recycled materials. Obviously, the suppliers' demands for these two materials depend on their prices. In this setting, a sustainable supply chain is established including the collector, cleaner, and recycler firms to price the collected, cleaned, and fragmented plastic bottles in the market as follows.

The collector collects the used plastic bottles and then transfers them to suppliers. In fact, to meet the suppliers' demand for the recycled materials, he sells the collected bottles to the recycler and then the recycler cleans and fragments them. Finally, the recycled materials are transferred by the recycler to suppliers. Moreover, to meet the demand of the cleaned bottles, the collector cleans the collected bottles himself or through a cleaner. Note that the collector is not equipped with bottles cleaning technology, but he can buy the required equipment and establish this technology paying a setup cost or clean the collected bottles via the cleaner. In this point of view, two different structures are considered for transferring the cleaned bottles to suppliers. In the first structure (hereafter referred to as "structure S1"), the collector cleans the collected bottles through the cleaner by giving a share of the profit obtained from selling in this channel to him. Furthermore, in the second structure (hereafter referred to as "structure S2"), the collector establishes the bottles cleaning technology paying a setup cost.

Notations used in this study are defined as follows:

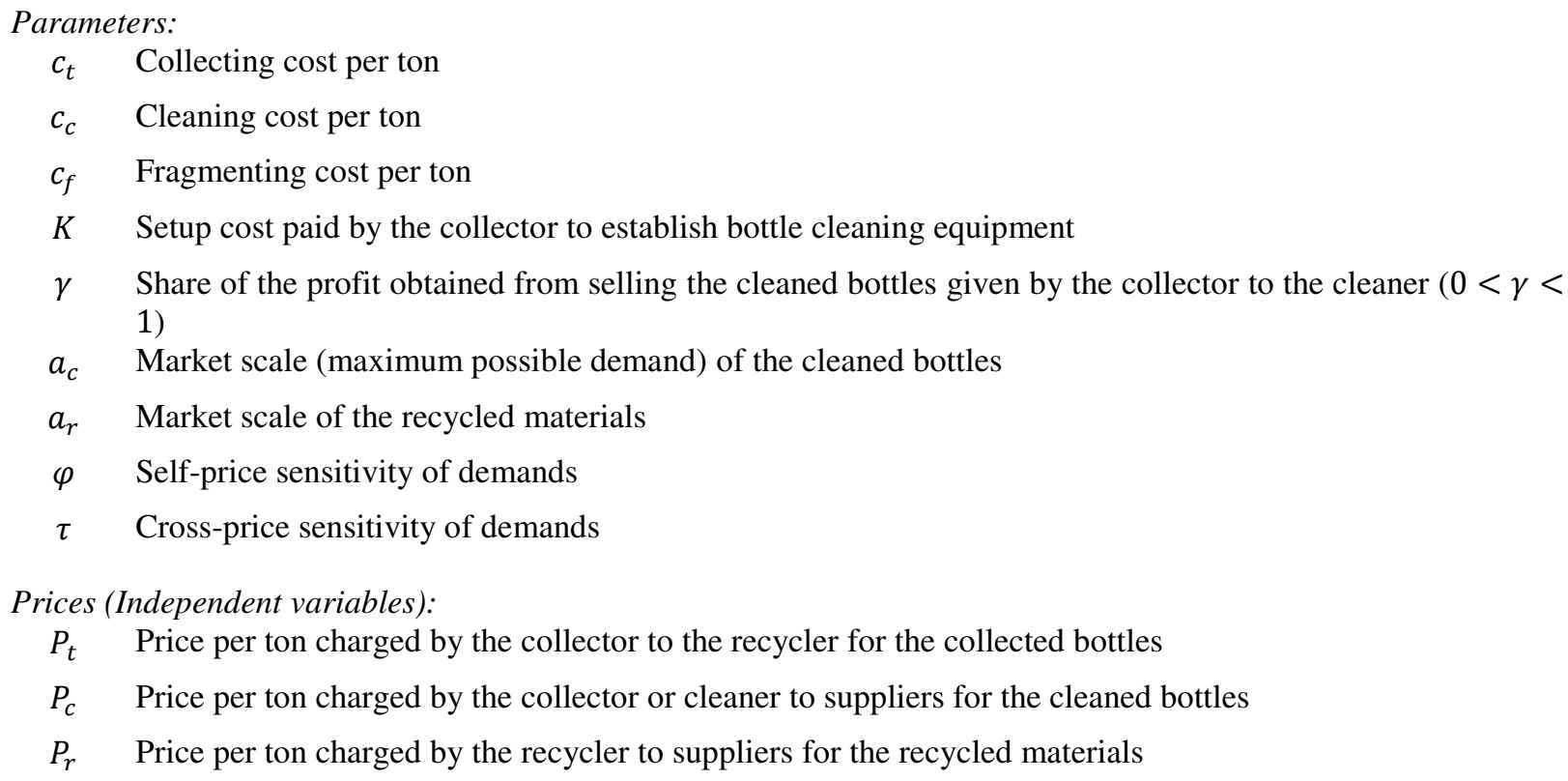

The suppliers' demands of the cleaned and recycled materials are assumed to be a linear function of the prices set for them. These demands are as follows:

$D_{c}=a_{c}-\varphi P_{c}+\tau P_{r}$

$D_{r}=a_{r}-\varphi P_{r}+\tau P_{c}$ 
follows:

Moreover, the profit functions of the collector, cleaner, recycler, and whole system are formulated as $\pi_{t}= \begin{cases}\pi_{t}^{S 1}=(1-\gamma)\left(P_{c}-c_{t}-c_{c}\right) D_{c}+\left(P_{t}-c_{t}\right) D_{r} & \text { under S1 } \\ \pi_{t}^{S 2}=\left(P_{c}-c_{t}-c_{c}\right) D_{c}+\left(P_{t}-c_{t}\right) D_{r}-K & \text { under S2 }\end{cases}$

$\pi_{c}=\gamma\left(P_{c}-c_{t}-c_{c}\right) D_{c}$

$\pi_{r}=\left(P_{r}-P_{t}-c_{c}-c_{f}\right) D_{r}$

$\pi_{s}= \begin{cases}\pi_{s}^{S 1}=\pi_{t}{ }^{S 1}+\pi_{c}+\pi_{r}=\left(P_{c}-c_{t}-c_{c}\right) D_{c}+\left(P_{r}-c_{t}-c_{c}-c_{f}\right) D_{r} & \text { under S1 } \\ \pi_{s}{ }^{S 2}=\pi_{t}{ }^{S 2}+\pi_{r}=\left(P_{c}-c_{t}-c_{c}\right) D_{c}+\left(P_{r}-c_{t}-c_{c}-c_{f}\right) D_{r}-K & \text { under S2 }\end{cases}$

Below, some assumptions are considered in the problem:

(1) The collector has enough capacity to meet the suppliers' demands for the cleaned and recycled materials.

(2) The considered costs (i.e., the collecting, cleaning, and fragmenting costs) are the same for the members.

(3) $\varphi>\tau$ : The self-price sensitivity is higher than the cross-price sensitivity of the demands.

(4) $a_{c} \leq a_{r}$ : More suppliers prefer to buy the recycled materials rather than to purchase the cleaned bottles and then fragment them themselves.

(5) $a_{c}-\varphi\left(c_{t}+c_{c}\right)+\tau\left(c_{t}+c_{c}+c_{f}\right) \geq 0, a_{r}-\varphi\left(c_{t}+c_{c}+c_{f}\right)+\tau\left(c_{t}+c_{c}\right) \geq 0$ : The suppliers' demands are nonnegative when the profit margins of the members are equal to zero (i.e., $P_{c}=c_{t}+c_{c}, P_{t}=c_{t}, P_{r}=$ $\left.c_{t}+c_{c}+c_{f}\right)$.

To set the considered prices rationally, the following constraints are also incorporated into the problem:

(2) $P_{c} \geq c_{t}+c_{c}, P_{t} \geq c_{t}$, and $P_{r} \geq P_{t}+c_{c}+c_{f}$ : The unit profit margins are nonnegative.

(3) $P_{c} \geq P_{t}+c_{c}$ : The price of the cleaned bottles is greater than the sum of the price set for the collected bottles and the cleaning cost. Otherwise, it is beneficial for the recycler to buy the cleaned bottles and then fragment them.

(4) $P_{r} \geq P_{c}+c_{f}$ : The price of the recycled materials is higher than the sum of the price set for the cleaned bottles and the fragmenting cost. Otherwise, all suppliers meet their required materials via the recycler.

(5) $D_{c}, D_{r} \geq 0$ : The suppliers' demands are nonnegative.

These constraints are summarized as follows:

$P_{c} \geq c_{t}+c_{c}, \quad P_{t} \geq c_{t}, \quad P_{r} \geq P_{t}+c_{c}+c_{f}, \quad P_{c} \geq P_{t}+c_{c}, \quad P_{r} \geq P_{c}+c_{f}, \quad D_{c}, D_{r} \geq 0$

Now, decisions are determined applying the game-theoretic approach under different interactions among the members.

\section{Game-theoretic approach}

In this section, the game theory is used to set decisions under the structures S1 and S2. Considering the competitive and cooperative interactions among the members, it is investigated which of the following structures is more beneficial from the collector's point of view?

- Structure S1: Cleaning the collected bottles through the cleaner by giving a share of the profit obtained from selling in this channel to him.

- $\quad$ Structure S2: Establishing the bottles cleaning technology by paying a setup cost.

In what follows, attempts are made to answer to Research Question 1 presented in Section 1. Note that all theorems appearing in this section are proved in Appendix A (in electronic companion).

\section{1. $\quad$ Nash game}

Under Nash game, the players make their decisions independently and simultaneously.

\subsubsection{Nash game under structure S1 (Nash I game)}

In Nash I game developed under the structure S1, the collector, cleaner, and recycler respectively set the price of the collected bottles to the recycler, the price of the cleaned bottles to suppliers, and the price of the recycled materials to suppliers. The decisions are made independently and simultaneously by maximizing the players' profits. Nash I game is formulated as follows: 


$$
\left\{\begin{array}{l}
\max _{P_{t}} \pi_{t}^{S 1}=(1-\gamma)\left(P_{c}-c_{t}-c_{c}\right) D_{c}+\left(P_{t}-c_{t}\right) D_{r} \\
\max _{P_{c}} \pi_{c}=\gamma\left(P_{c}-c_{t}-c_{c}\right) D_{c} \\
\max _{P_{r}} \pi_{r}=\left(P_{r}-P_{t}-c_{c}-c_{f}\right) D_{r} \\
\text { s.t. } P_{c} \geq c_{t}+c_{c}, P_{t} \geq c_{t}, \quad P_{r} \geq P_{t}+c_{c}+c_{f}, P_{c} \geq P_{t}+c_{c}, P_{r} \geq P_{c}+c_{f}, D_{c}, D_{r} \geq 0
\end{array}\right.
$$

(Problem A)

Theorem 1. Under Nash I game, the equilibrium prices are as follows:

$$
\left\{\begin{array}{l}
P_{t}^{N I}=\frac{\tau\left(a_{r}+\tau c_{c}\right)+\varphi\left(2 a_{c}+(\tau-2 \varphi) c_{c}+\tau c_{f}+2 \varphi c_{t}\right)}{4 \varphi^{2}-\tau^{2}-\tau \varphi} \\
P_{c}^{N I}=\frac{\tau a_{r}+\varphi\left(2 a_{c}+\tau c_{f}+2 \varphi\left(c_{t}+c_{c}\right)\right)}{4 \varphi^{2}-\tau^{2}-\tau \varphi} \\
P_{r}^{N I}=\frac{(\tau+\varphi) a_{c}+\varphi\left(2 a_{r}+(\tau+\varphi)\left(c_{t}+c_{c}\right)+2 \varphi c_{f}\right)}{4 \varphi^{2}-\tau^{2}-\tau \varphi}
\end{array}\right.
$$

Note that the concavity of the profit functions and the feasibility of the equilibrium prices in all developed games are investigated in Appendix A (in electronic companion).

\subsection{2. $\quad$ Nash game under structure S2 (Nash II game)}

Under Nash II game concerning the structure S2, the collector and recycler specify the prices independently and simultaneously by maximizing their own profit functions. In this situation, the collector sets the price of the collected bottles to the recycler as well as the price of the cleaned bottles to suppliers. Furthermore, the recycler gives the price of the recycled materials to suppliers. Nash II game is modelled as follows:

$$
\left\{\begin{array}{l}
\max _{P_{t}, P_{c}} \pi_{t}{ }^{S 2}=\left(P_{c}-c_{t}-c_{c}\right) D_{c}+\left(P_{t}-c_{t}\right) D_{r}-K \\
\max _{P_{r}} \pi_{r}=\left(P_{r}-P_{t}-c_{c}-c_{f}\right) D_{r} \\
\text { s. t. } P_{c} \geq c_{t}+c_{c}, P_{t} \geq c_{t}, \quad P_{r} \geq P_{t}+c_{c}+c_{f}, P_{c} \geq P_{t}+c_{c}, \quad P_{r} \geq P_{c}+c_{f}, \quad D_{c}, D_{r} \geq 0
\end{array}\right.
$$

(Problem B)

Theorem 2. The equilibrium pricing strategy in Nash II game is:

$$
\left\{\begin{array}{l}
P_{t}^{N I I}=\frac{\tau\left(a_{r}+\tau c_{c}\right)+\varphi\left(2 a_{c}-(2 \varphi-\tau) c_{c}+\tau c_{f}+2(\varphi-\tau) c_{t}\right)}{(\varphi-\tau)(4 \varphi+\tau)} \\
P_{c}^{N I I}=\frac{\tau a_{r}+\varphi\left(2 a_{c}+2(\varphi-\tau)\left(c_{t}+c_{c}\right)+\tau c_{f}\right)}{(\varphi-\tau)(4 \varphi+\tau)} \\
P_{r}^{N I I}=\frac{(\tau+\varphi) a_{c}+(2 \varphi-\tau) a_{r}+\left(\varphi^{2}-\tau^{2}\right)\left(c_{t}+c_{c}\right)+\varphi(2 \varphi-\tau) c_{f}}{(\varphi-\tau)(4 \varphi+\tau)}
\end{array}\right.
$$

\subsection{Stackelberg game}

Under Stackelberg game, first, the leader player sets his decisions. Then, the follower player specifies his response based on the leader's decisions.

\subsection{1. $\quad$ Stackelberg game under structure S1 (Stackelberg I game)}

In Stackelberg I game developed under the structure S1, the collector as the leader declares the price of the collected bottles to the recycler at the first level. Then, at the second level, the cleaner and recycler as the followers respectively set the prices of the cleaned and recycled materials to suppliers independently and simultaneously. Stackelberg I game model is as follows:

$$
\left\{\begin{array}{l}
\text { First level: } \max _{P_{t}} \pi_{t}{ }^{S 1}=(1-\gamma)\left(P_{c}-c_{t}-c_{c}\right) D_{c}+\left(P_{t}-c_{t}\right) D_{r} \\
\text { Second level: }\left\{\begin{array}{l}
\max _{P_{c}} \pi_{c}=\gamma\left(P_{c}-c_{t}-c_{c}\right) D_{c} \\
\max _{P_{r}} \pi_{r}=\left(P_{r}-P_{t}-c_{c}-c_{f}\right) D_{r}
\end{array}\right. \\
\text { s.t. } P_{c} \geq c_{t}+c_{c}, P_{t} \geq c_{t}, \quad P_{r} \geq P_{t}+c_{c}+c_{f}, \quad P_{c} \geq P_{t}+c_{c}, P_{r} \geq P_{c}+c_{f}, D_{c}, D_{r} \geq 0
\end{array}\right.
$$

Similar to the previous games, one can derive the following theorem: 
Theorem 3. The equilibrium pricing policy in Stackelberg I game is as follows:

$\left\{\begin{array}{l}P_{t}^{S I}=\frac{\tau B_{2} a_{c}+2 \varphi B_{3} a_{r}-B_{4} c_{c}-B_{5} c_{f}+B_{6} c_{t}}{2 B_{1}} \\ P_{c}^{S I}=\frac{\varphi B_{7} a_{c}+2 \tau B_{8} a_{r}+\varphi\left(B_{9}\left(c_{t}+c_{c}\right)+\tau B_{10} c_{f}\right)}{2 B_{1}} \\ P_{r}^{S I}=\frac{\tau B_{11} a_{c}+\varphi\left(2 B_{8} a_{r}+B_{12}\left(c_{t}+c_{c}\right)+\varphi B_{10} c_{f}\right)}{B_{1}}\end{array}\right.$

where,

$B_{1}=8 \varphi^{4}+\tau^{4}-(7-\gamma) \tau^{2} \varphi^{2}$

$B_{2}=4(2-\gamma) \varphi^{2}-\tau^{2}$

$B_{3}=4 \varphi^{2}-\gamma \tau^{2}$

$B_{4}=\tau^{4}-\tau^{3} \varphi+2 \gamma \tau^{3} \varphi-8 \tau^{2} \varphi^{2}+2 \gamma \tau^{2} \varphi^{2}-4 \gamma \tau \varphi^{3}+8 \varphi^{4}$

$B_{5}=\tau^{4}-8 \tau^{2} \varphi^{2}+2 \gamma \tau^{2} \varphi^{2}+8 \varphi^{4}$

$B_{6}=\tau^{4}-6 \tau^{2} \varphi^{2}+4 \gamma \tau \varphi^{3}+8 \varphi^{4}-2 \gamma \varphi \tau^{3}+\varphi \tau^{3}$

$B_{7}=8 \varphi^{2}-3 \tau^{2}$

$B_{8}=3 \varphi^{2}-\tau^{2}$

$B_{9}=-\tau^{3}-5 \tau^{2} \varphi+10 \gamma \tau^{2} \varphi+2 \tau \varphi^{2}+8 \varphi^{3}$

$B_{10}=2 \varphi^{2}-\tau^{2}$

$B_{11}=(4-\gamma) \varphi^{2}-\tau^{2}$

$B_{12}=-\tau^{3}-\tau^{2} \varphi+2 \tau \varphi^{2}+\gamma \tau \varphi^{2}+2 \varphi^{3}$

\subsection{2. $\quad$ Stackelberg game under structure S2 (Stackelberg II game)}

Under Stackelberg II game, first, the collector as the leader makes the price of the collected bottles to the recycler and the price of the cleaned bottles to suppliers. Then, the recycler as the follower specifies the price of the recycled materials to suppliers. Stackelberg II game is formulated as follows:

$\left\{\begin{array}{l}\text { First level: } \max _{P_{t}, P_{c}} \pi_{t}{ }^{S 2}=\left(P_{c}-c_{t}-c_{c}\right) D_{c}+\left(P_{t}-c_{t}\right) D_{r}-K \\ \text { Second level: } \max _{P_{r}} \pi_{r}=\left(P_{r}-P_{t}-c_{c}-c_{f}\right) D_{r} \\ \text { s.t. } P_{c} \geq c_{t}+c_{c}, P_{t} \geq c_{t}, \quad P_{r} \geq P_{t}+c_{c}+c_{f}, P_{c} \geq P_{t}+c_{c}, P_{r} \geq P_{c}+c_{f}, \quad D_{c}, D_{r} \geq 0\end{array}\right.$

(Problem D)

Theorem 4. The equilibrium pricing strategy under Stackelberg II game is:

$$
\left\{\begin{array}{l}
P_{t}{ }^{S I I}=\frac{\tau a_{c}+\varphi a_{r}+\left(\tau^{2}-\varphi^{2}\right)\left(c_{c}+c_{f}-c_{t}\right)}{2\left(\varphi^{2}-\tau^{2}\right)} \\
P_{c}^{S I I}=\frac{\varphi a_{c}+\tau a_{r}+\left(\varphi^{2}-\tau^{2}\right)\left(c_{c}+c_{t}\right)}{2\left(\varphi^{2}-\tau^{2}\right)} \\
P_{r}^{S I I}=\frac{2 \tau \varphi a_{c}+\left(3 \varphi^{2}-\tau^{2}\right) a_{r}+\left(\varphi^{2}-\tau^{2}\right)\left((\tau+\varphi)\left(c_{t}+c_{c}\right)+\varphi c_{f}\right)}{4 \varphi\left(\varphi^{2}-\tau^{2}\right)}
\end{array}\right.
$$

\subsection{Centralized game}

Under Centralized game, all players act in union and specify their decisions by maximizing the profit of the whole system.

\subsection{1. $\quad$ Centralized game under structure S1 (Centralized I game)}

In Centralized I game established under the structure S1, the collector, cleaner, and recycler agree to perform in union and specify the prices of the cleaned and recycled materials to suppliers jointly and simultaneously. Centralized I game model is as follows:

$\left\{\begin{array}{l}\max _{P_{c}, P_{r}} \pi_{s}{ }^{S 1}=\pi_{t}{ }^{S 1}+\pi_{c}+\pi_{r}=\left(P_{c}-c_{t}-c_{c}\right) D_{c}+\left(P_{r}-c_{t}-c_{c}-c_{f}\right) D_{r} \\ \text { s.t. } P_{c} \geq c_{t}+c_{c}, \quad P_{r} \geq P_{c}+c_{f}, \quad D_{c}, D_{r} \geq 0\end{array}\right.$

(Problem E)

Theorem 5. In Centralized I game, the equilibrium prices of the cleaned and recycled materials to suppliers are obtained as follows: 


$$
\left\{\begin{array}{l}
P_{c}^{C I}=\frac{\varphi a_{c}+\tau a_{r}+\left(\varphi^{2}-\tau^{2}\right)\left(c_{c}+c_{t}\right)}{2\left(\varphi^{2}-\tau^{2}\right)} \\
P_{r}^{C I}=\frac{\tau a_{c}+\varphi a_{r}+\left(\varphi^{2}-\tau^{2}\right)\left(c_{c}+c_{f}+c_{t}\right)}{2\left(\varphi^{2}-\tau^{2}\right)}
\end{array}\right.
$$

Due to maximizing the profit value of the whole system under Centralized I game, this profit value is greater than under Nash I game in which the players compete to set their decisions, i.e., $\pi_{s}{ }^{C I} \geq \pi_{s}{ }^{N I}=\pi_{t}{ }^{N I}+$ $\pi_{c}{ }^{N I}+\pi_{r}{ }^{N I}$, where symbols $C I$ and $N I$ denote Centralized I and Nash I games, respectively. In this setting, the shares of the extra profit for the players obtained from the whole system cooperation under Centralized I game compared with Nash I game, the players' profits, and the price of the collected bottles set by the collector to the recycler are neglected in Centralized I game. Now, Nash bargaining process (Nash 1950) is applied to calculate these values in Centralized I game based on the negotiation powers of the players.

Assume that $\lambda_{t}, \lambda_{c}$, and $\lambda_{r}$ respectively are the negotiation powers of the collector, cleaner, and recycler and they respectively receive the shares $\Delta \pi_{t}{ }^{C I}=\pi_{t}{ }^{C I}-\pi_{t}{ }^{N I}, \Delta \pi_{c}{ }^{C I}=\pi_{c}{ }^{C I}-\pi_{c}{ }^{N I}$, and $\Delta \pi_{r}{ }^{C I}=\pi_{r}{ }^{C I}-\pi_{r}{ }^{N I}$ of the increased profit obtained from the whole system cooperation under Centralized I game compared with Nash I game, i.e., $\Delta \pi_{s}{ }^{C I}=\pi_{s}{ }^{C I}-\pi_{s}{ }^{N I}$. Applying Nash bargaining process, the following theorem can be given.

Theorem 6. The shares of the extra profit for the players in Centralized I game are:

$\left\{\begin{aligned} \Delta \pi_{t}{ }^{C I} & =\frac{\lambda_{t}}{\lambda_{t}+\lambda_{c}+\lambda_{r}} \Delta \pi_{s}{ }^{C I} \\ \Delta \pi_{c}{ }^{C I} & =\frac{\lambda_{c}}{\lambda_{t}+\lambda_{c}+\lambda_{r}} \Delta \pi_{s}{ }^{C I} \\ \Delta \pi_{r}{ }^{C I} & =\frac{\lambda_{r}}{\lambda_{t}+\lambda_{c}+\lambda_{r}} \Delta \pi_{s}{ }^{C I}\end{aligned}\right.$

The profit values of the players under Centralized I game are also calculated using following theorem.

Theorem 7. The players' profits under Centralized I game are given as follows:

$\left\{\begin{array}{l}\pi_{t}{ }^{C I}=\pi_{t}{ }^{N I}+\frac{\lambda_{t}}{\lambda_{t}+\lambda_{c}+\lambda_{r}} \Delta \pi_{s}{ }^{C I} \\ \pi_{c}{ }^{C I}=\pi_{c}{ }^{N I}+\frac{\lambda_{c}}{\lambda_{t}+\lambda_{c}+\lambda_{r}} \Delta \pi_{s}{ }^{C I} \\ \pi_{r}{ }^{C I}=\pi_{r}{ }^{N I}+\frac{\lambda_{r}}{\lambda_{t}+\lambda_{c}+\lambda_{r}} \Delta \pi_{s}{ }^{C I}\end{array}\right.$

Furthermore, the price of the collected bottles specified by the collector to the recycler in Centralized I game is calculated by solving relation (3) with respect to $P_{t}$.

Theorem 8. The price of the collected bottles set by the collector to the recycler under Centralized I game is:

$P_{t}^{C I}=\frac{\pi_{t}^{C I}-(1-\gamma)\left(P_{c}^{C I}-c_{t}-c_{c}\right) D_{c}^{C I}}{D_{r}^{C I}}+c_{t}$

where, $D_{c}{ }^{C I}$ and $D_{r}{ }^{C I}$ respectively are the suppliers' demands for the cleaned and recycled materials in Centralized I game.

\subsubsection{Centralized game under structure S2 (Centralized II game)}

In Centralized II game, the collector and recycler cooperate and set the prices by maximizing the profit of the whole system under the structure S2. Centralized II game is formulated as follows:

$\left\{\max _{P_{c}, P_{r}} \pi_{s}^{S 2}=\pi_{t}^{S 2}+\pi_{c}+\pi_{r}=\left(P_{c}-c_{t}-c_{c}\right) D_{c}+\left(P_{r}-c_{t}-c_{c}-c_{f}\right) D_{r}-K\right.$

$\left\{\begin{array}{l}\text { s. t. } P_{c} \geq c_{t}+c_{c}, P_{r} \geq P_{c}+c_{f}, D_{c}, D_{r} \geq 0\end{array}\right.$

(Problem F)

Comparing the problems considered in Centralized I and II games, one can derive that the selling prices to suppliers set in these games are the same.

Using Nash bargaining process, the shares of the increased profit for the players under Centralized II game compared with Nash II game, the players' profits, and the price of the collected bottles are calculated based on the negotiation powers of the collector and recycler. 
Theorem 9. Under Centralized II game, the shares of the increased profit for the players are as follows:

$\left\{\begin{array}{l}\Delta \pi_{t}{ }^{C I I}=\frac{\lambda_{t}}{\lambda_{t}+\lambda_{r}} \Delta \pi_{s}{ }^{C I I} \\ \Delta \pi_{r}{ }^{C I I}=\frac{\lambda_{r}}{\lambda_{t}+\lambda_{r}} \Delta \pi_{s}{ }^{C I I}\end{array}\right.$

where, $\Delta \pi_{s}{ }^{C I I}=\pi_{s}{ }^{C I I}-\pi_{s}{ }^{N I I}$ is the extra profit of the whole system under Centralized II game compared with Nash II game.

Theorem 10. The players' profits in Centralized II game are:

$\left\{\begin{array}{l}\pi_{t}{ }^{C I I}=\pi_{t}{ }^{N I I}+\frac{\lambda_{t}}{\lambda_{t}+\lambda_{r}} \Delta \pi_{s}{ }^{C I I} \\ \pi_{r}{ }^{C I I}=\pi_{r}{ }^{N I I}+\frac{\lambda_{r}}{\lambda_{t}+\lambda_{r}} \Delta \pi_{s}{ }^{C I I}\end{array}\right.$

Theorem 11. Under Centralized II game, the price of the collected bottles determined by the collector to the recycler is as follows:

$P_{t}^{C I I}=\frac{\pi_{t}^{C I I}-\left(P_{c}^{C I I}-c_{t}-c_{c}\right) D_{c}^{C I I}+K}{D_{r}^{C I I}}+c_{t}$

where, $D_{c}{ }^{C I I}$ and $D_{r}{ }^{C I I}$ are the suppliers' demands under Centralized II game.

Due to various interactions among the players, different games can be established to price the collected, cleaned, and recycled bottles in the market. If the players compete to set the prices independently with similar decision powers, they can make decisions under Nash game. When the decision power of the collector is higher than of the others, they can specify the prices under Stackelberg game. Moreover, Centralized game can be developed to determine the prices by maximizing the profit value of whole system.

\section{Results and discussion}

In this section, the obtained decisions are discussed and the results are revealed.

\subsection{Comparisons of the obtained strategies under the developed games}

To answer to Research Question 2 introduced in Section 1, under the established games, it is investigated which of the structures S1 or S2 can be more beneficial from the collector's point of view?

Result 1. Comparing the collector's profits given by the games developed under the structures S1 and S2, one can derive that:

(i) $\quad \pi_{t}^{N I}<\pi_{t}^{N I I}$

(ii) $\pi_{t} S I<\pi_{t}^{S I I}$

if $K<K^{N}$

(iii) $\pi_{t}{ }^{C I}<\pi_{t}{ }^{C I I}$

if $K<K^{S}$

if $K<K^{C}$

where, symbols $K^{N}, K^{S}$, and $K^{C}$ are defined in Appendix A (in electronic companion).

Managerial Insight 1. Under Nash, Stackelberg, and Centralized games, it is more beneficial for the collector to establish the bottles cleaning technology himself, if the setup cost of this technology is lower than $K^{N}, K^{S}$, and $K^{C}$, respectively.

Below, to answer to Research Question 3, the given decisions are compared under the investigated games. Note that the provided results can be straightforwardly derived using assumptions (3)-(5) and after some manipulations.

Result 2. The following relations hold among the prices obtained from the games:

$\begin{aligned} & \text { (i) } \begin{cases}P_{t}{ }^{C I} \leq P_{t}{ }^{N I} \leq P_{t}{ }^{S I} & \text { under structure } S 1 \\ P_{t}{ }^{C I I} \leq P_{t}{ }^{I I} \leq P_{t}{ }^{S I I} & \text { under structure } S 2\end{cases} \\ & \text { (ii) } \begin{cases}P_{c}{ }^{N I} \leq P_{c}{ }^{S I} \leq P_{c}{ }^{C I} & \text { under structure } S 1 \\ P_{c}{ }^{N I I} \leq P_{c}{ }^{S I I} \leq P_{c}{ }^{C I I} & \text { under structure } S 2\end{cases} \\ & \text { (iii) } \begin{cases}P_{r}{ }^{C I} \leq P_{r}{ }^{N I} \leq P_{r}{ }^{S I} & \text { under structure } S 1 \\ P_{r}{ }^{C I I} \leq P_{r}{ }^{N I I} \leq P_{r}{ }^{S I I} & \text { under structure } S 2\end{cases} \end{aligned}$ 
Managerial Insight 2. Under the structures S1 and S2, Centralized and Stackelberg games respectively give the lowest and the highest prices for the collected bottles and the recycled materials, while the lowest and the highest prices for the cleaned bottles are obtained under Nash and Centralized games, respectively.

Result 3. The following relations can be given for the suppliers' demands:

(i) $\left\{\begin{array}{l}D_{c}{ }^{C I} \leq D_{c}{ }^{N I} \leq D_{c}{ }^{S I} \\ D_{c}{ }^{C I I} \leq D_{c}{ }^{N I I} \leq D_{c}\end{array}\right.$

under structure $S 1$

under structure $S 2$

(ii)

$\begin{cases}D_{r}{ }^{S I} \leq D_{r}{ }^{N I} \leq D_{r}{ }^{C I} & \text { under structure } S 1 \\ D_{r}{ }^{\text {SII }} \leq D_{r}{ }^{N I I} \leq D_{r}{ }^{C I I} & \text { under structure } S 2\end{cases}$

Managerial Insight 3. Centralized and Stackelberg games respectively lead to the shortest and the greatest demands for the cleaned bottles under structures $S 1$ and S2. This inference is reversed for the demands of the recycled materials.

Suppliers are price sensitive. Thus, higher prices lead to lower demands. Consequently, it can be stated that Managerial Insight 3 is obtained from Managerial Insight 2.

Result 4. The following inferences can be derived for the profits:

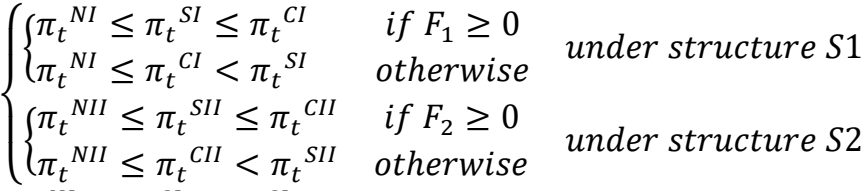

$$
\begin{aligned}
& \left\{\pi_{c}{ }^{N I} \leq \pi_{c}{ }^{S I} \leq \pi_{c}{ }^{C I} \quad \text { if } F_{1} \geq 0\right. \\
& \left\{\pi_{c}{ }^{N I} \leq \pi_{c}{ }^{C I}<\pi_{c}{ }^{S I} \quad\right. \text { otherwise }
\end{aligned}
$$

$\left\{\pi_{r} S I \leq \pi_{r} N I \leq \pi_{r} C I\right.$ under structure $S 1$

$$
\left\{\pi_{r}{ }^{S I I} \leq \pi_{r}{ }^{N I I} \leq \pi_{r}{ }^{C I I}\right.
$$

under structure $S 2$

$\int \pi_{s}{ }^{S I} \leq \pi_{s}{ }^{N I} \leq \pi_{s}{ }^{C I}$

under structure $S 1$

$\left\{\pi_{s}{ }^{S I I} \leq \pi_{s}{ }^{N I I} \leq \pi_{s}{ }^{C I I}\right.$

under structure $S 2$

Managerial Insight 4. Nash game leads to the lowest profits for the collector and cleaner. Moreover, the highest and the lowest profits for the recycler and the whole system are respectively obtained under Centralized and Stackelberg games.

Regarding Theorems 7 and 10, the profit values under Centralized game are greater than under Nash game. In Stackelberg game, the collector acts as the leader and the recycler is considered as the follower. Thus, it is expected that the collector's profit given by Stackelberg game is higher than by Nash game. This inference holds for the cleaner's profit by giving a share of the collector's profit to the cleaner under the structure S1. Furthermore, this conclusion is reversed for the profit values of the recycler and the whole system.

Result 5. Under Centralized games, one can derive that $\pi_{S}{ }^{C I I}=\pi_{S}{ }^{C I}-K$.

Managerial Insight 5. From the whole system's point of view, it is more beneficial to clean the collected bottles via the cleaner by giving a share of the profit obtained from selling in this channel to him.

\subsection{Numerical example}

In this section, a real case is presented to well illustrate the research problem. Consider an instance with the parameters values given in Table 1. Note these values have been estimated under a supply chain structure similar to that investigated on the current study in a market of textile industry in Iran. The results obtained from the developed games for this example are summarized in Table 2.

Table 1. The values of the parameters in the numerical example

\begin{tabular}{lccccccccc}
\hline Parameter & $c_{t}$ & $c_{c}$ & $c_{f}$ & $a_{c}$ & $a_{r}$ & $\varphi$ & $\tau$ & $K$ & $\gamma$ \\
\hline Value & 100 & 20 & 40 & 2000 & 4000 & 6.0 & 0.3 & 100000 & 0.4 \\
\hline
\end{tabular}


Table 2. The results obtained from the investigated games for the numerical example

\begin{tabular}{|c|c|c|c|c|c|}
\hline \multirow{2}{*}{ Games } & \multicolumn{3}{|c|}{ Prices } & \multicolumn{2}{|c|}{ Demands } \\
\hline & $P_{t}$ & $P_{c}$ & $P_{r}$ & $D_{c}$ & $D_{r}$ \\
\hline Nash I & 218.63 & 238.63 & 478.62 & 711.79 & 1199.90 \\
\hline Nash II & 221.72 & 241.72 & 480.23 & 693.78 & 1191.11 \\
\hline Stackelberg I & 361.23 & 240.42 & 549.96 & 722.49 & 772.36 \\
\hline Stackelberg II & 362.52 & 243.79 & 550.69 & 702.45 & 769.00 \\
\hline Centralized I & - & 243.79 & 422.52 & 664.00 & 1538.00 \\
\hline \multirow[t]{3}{*}{ Centralized II } & - & 243.79 & 422.52 & 664.00 & 1538.00 \\
\hline & \multicolumn{5}{|c|}{ Profits } \\
\hline & $\pi_{t}$ & & $\pi_{c}$ & $\pi_{r}$ & $\pi_{s}$ \\
\hline Nash I & 193011.26 & & 33776.55 & 239959.47 & 466747.28 \\
\hline Nash II & 129420.00 & & - & 236457.61 & 365877.62 \\
\hline Stackelberg I & 253966.56 & & 34799.84 & 99424.36 & 388190.76 \\
\hline Stackelberg II & 188838.43 & & - & 98560.17 & 287398.60 \\
\hline Centralized I & - & & - & - & 485958.76 \\
\hline Centralized II & - & & - & - & 385958.76 \\
\hline
\end{tabular}

Let the negotiation powers of the collector, cleaner, and recycler respectively are equal to $\lambda_{t}=0.5, \lambda_{c}=$ 0.2 , and $\lambda_{r}=0.3$. In this situation, the shares of the extra profit for the players obtained from the whole system cooperation, the players' profits, and the price of the collected bottles set by the collector to the recycler under Centralized games are calculated using Nash bargaining process. The related values are provided in Table 3.

Regarding the results, under Nash and Stackelberg games, it is more beneficial for the collector to clean the collected bottles via the cleaner by giving a share of the profit to him, whereas the collector receives higher profit under Centralized game, if he establishes the bottles cleaning technology himself by paying a setup cost.

Table 3. The results of Nash bargaining process for the numerical example

\begin{tabular}{|c|c|c|c|c|}
\hline \multicolumn{5}{|c|}{ Centralized I game } \\
\hline \multirow{2}{*}{ Shares of the extra profit } & $\Delta \pi_{s}$ & $\Delta \pi_{t}$ & $\Delta \pi_{c}$ & $\Delta \pi_{r}$ \\
\hline & 19211.49 & 9605.74 & 3842.30 & 5763.45 \\
\hline \multirow{2}{*}{ Profits } & $\pi_{t}$ & & & $\pi_{r}$ \\
\hline & 202617.00 & & & 245722.92 \\
\hline \multirow{2}{*}{ Price of the collected bottles } & \multicolumn{4}{|c|}{$P_{t}$} \\
\hline & \multicolumn{4}{|c|}{199.67} \\
\hline \multicolumn{5}{|c|}{ Centralized II game } \\
\hline \multirow{2}{*}{ Shares of the extra profit } & $\Delta \pi_{s}$ & & & $\Delta \pi_{r}$ \\
\hline & 120081.15 & & & 45030.43 \\
\hline \multirow{2}{*}{ Profits } & $\pi$ & & \multicolumn{2}{|c|}{$\pi_{r}$} \\
\hline & \multicolumn{2}{|c|}{204470.72} & \multicolumn{2}{|c|}{281488.04} \\
\hline \multirow{2}{*}{ Price of the collected bottles } & \multicolumn{4}{|c|}{$P_{t}$} \\
\hline & \multicolumn{4}{|c|}{114.48} \\
\hline
\end{tabular}

\subsection{Sensitivity analysis}

Now, to answer to Research Question 4, the effects of the parametric changes are investigated on the demands and profits given by the developed games. 


\subsubsection{Effects of the negotiation powers of the players}

Changes of the profits with respect to the negotiation powers of the players are specified regarding Theorems 7 and 10.

Managerial Insight 6. The more the negotiation power of a player, the more profit for him and the less profits for the others.

It is difficult to recognize how the profits are affected by changing $\gamma, \varphi$, and $\tau$. Thus, a sensitivity analysis is applied using the numerical example presented in Section 4.2.

\subsubsection{Effects of the share of the profit given by the collector to the cleaner}

Changes in the demands and profits with $\gamma$ are shown in Fig. 1. Since $\gamma$ is considered under the structure $\mathrm{S} 1$, its effects are only investigated on the profits related to this structure.

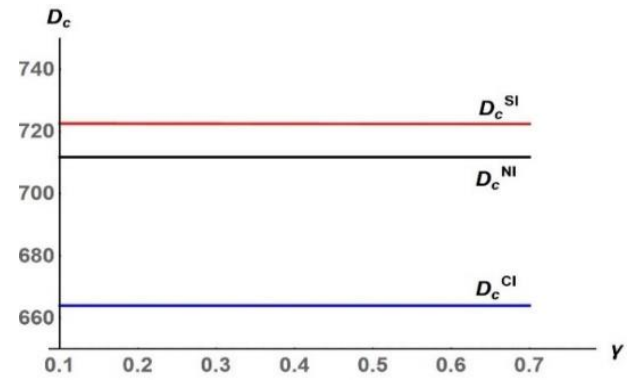

Fig. 1(a). Changes of $D_{c}$ with $\gamma$

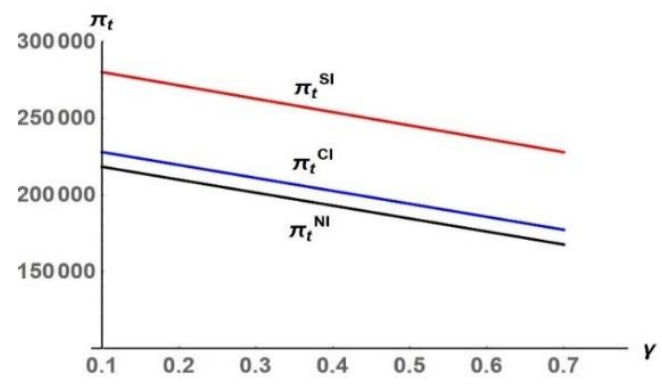

Fig. 1(c). Changes of $\pi_{t}$ with $\gamma$

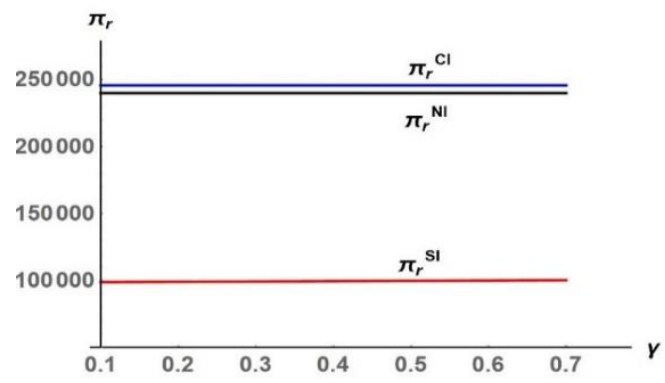

Fig. 1(e). Changes of $\pi_{r}$ with $\gamma$

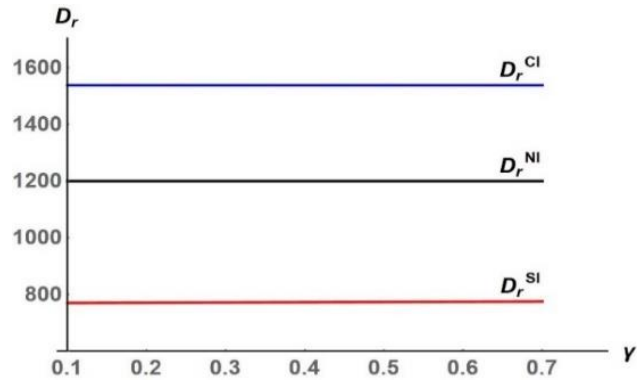

Fig. 1(b). Changes of $D_{r}$ with $\gamma$

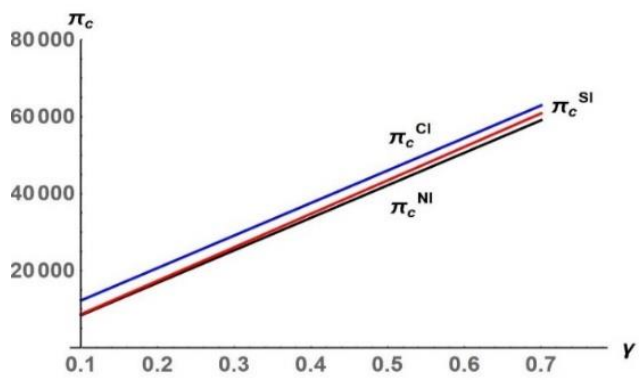

Fig. 1(d). Changes of $\pi_{c}$ with $\gamma$

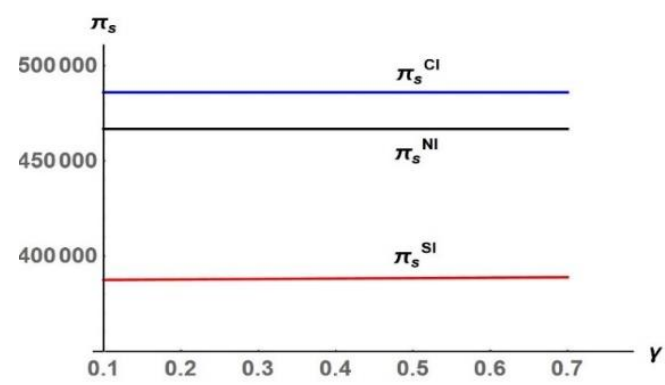

Fig. 1(f). Changes of $\pi_{s}$ with $\gamma$

Fig. 1. Changes of the demands and profits with $\gamma$

Managerial Insight 7. Under the structure S1, by increasing the share of the profit obtained from selling the cleaned bottles given by the collector to the cleaner, the collector's profit decreases, while the cleaner's profit increases, obviously. Moreover, changing this parameter does not affect the demands and profits of the recycler and whole system.

\subsubsection{Effects of the self-price and cross-price sensitivities of the demands}

Changes of the demands and profits obtained from the investigated games with respect to $\varphi$ and $\tau$ are exhibited in Fig. 2, simultaneously. 


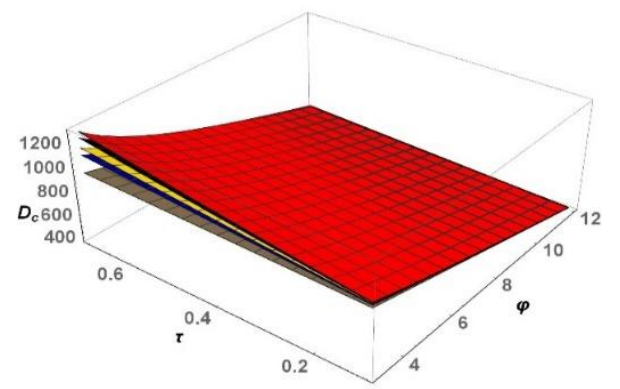

Fig. 2(a). Changes of $D_{c}$ with $\varphi$ and $\tau$

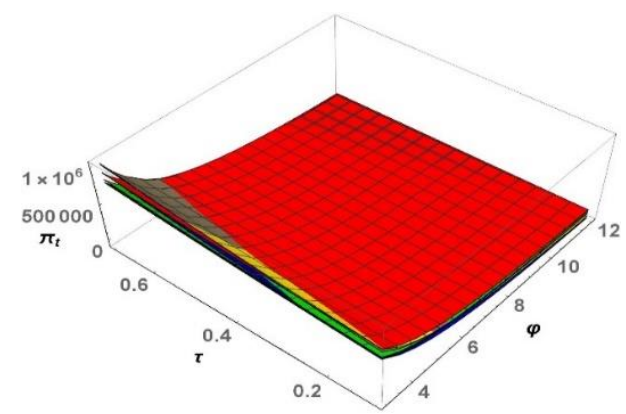

Fig. 2(c). Changes of $\pi_{t}$ with $\varphi$ and $\tau$

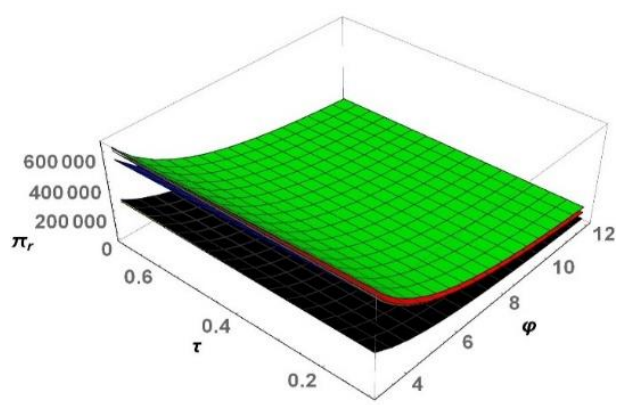

Fig. 2(e). Changes of $\pi_{r}$ with $\varphi$ and $\tau$

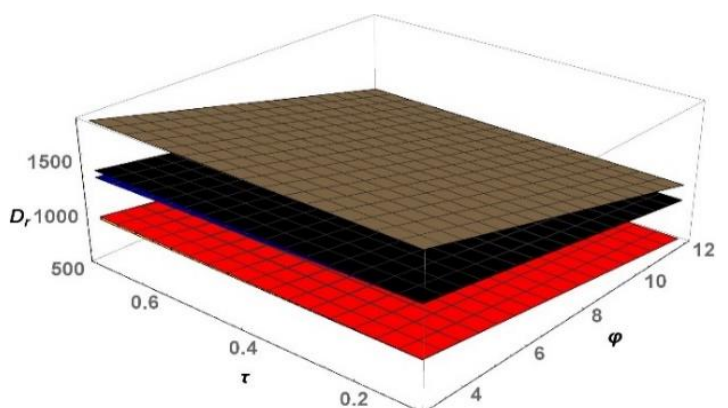

Fig. 2(b). Changes of $D_{r}$ with $\varphi$ and $\tau$

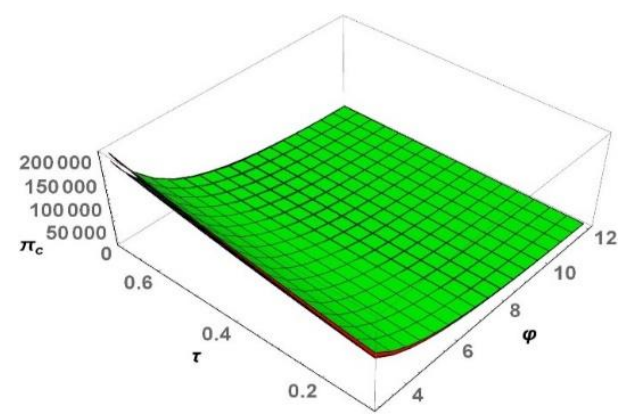

Fig. 2(d). Changes of $\pi_{c}$ with $\varphi$ and $\tau$

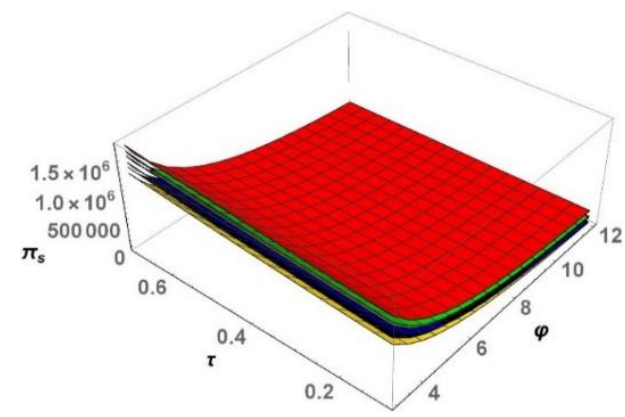

Fig. 2(f). Changes of $\pi_{s}$ with $\varphi$ and $\tau$

\section{NI $\square$ NII $\square$ SI \\ SII $\square$ Cl $\square$ CII}

Fig. 2. Changes of the demands and profits with $\varphi$ and $\tau$

Managerial Insight 8. The demands and profits decrease by increasing the self-price sensitivity of the suppliers' demands. Furthermore, the more the cross-price sensitivity of the suppliers' demands, the more demands and profits under the investigated games.

By increasing $\varphi$, the suppliers' demands decrease and this leads to lower profits obtained from the developed games. This insight is reversed as $\tau$ increases.

Managerial Insight 9. Policies that lead to decreasing the self-price and increasing the cross-price sensitivities of the suppliers' demands increase the volume of PET plastic bottles collected to be recycled and reused in textile industry. Therefore, these strategies can make the environment friendlier.

\section{Summary and conclusions}

In this paper, a sustainable supply chain consisting of the collector, cleaner, and recycler was established to collect, clean, and fragment PET plastic bottles and then reuse them in textile industry as appropriate substitutable for virgin materials. Some suppliers of textile industry purchase the cleaned and non-fragmented bottles and then they fragment them, whereas others procure the recycled materials (i.e., the cleaned and fragmented bottles). The collector collects the used plastic bottles. To meet demand of the recycled materials, 
the collector transfers a portion of the collected bottles to the recycler and then the recycler cleans and fragments them. Furthermore, to meet demand of the cleaned bottles, the collector cleans another portion of the collected bottles himself or via the cleaner. In this setting, two different structures were considered for transferring the cleaned bottles to suppliers. In the first structure, the collector cleans the collected bottles via the cleaner by giving a share of the profit to him, while he is equipped with the bottles cleaning technology by paying a setup cost in the second structure.

To make the decisions, the game-theoretic models including Nash, Stackelberg, and Centralized were developed under two considered structures.

Then, to analyze the effects of the investigated games on the given decisions, they were compared under these games. The obtained results are as follows:

- It is more beneficial for the collector to establish the bottles cleaning technology himself, if the setup cost of this technology is lower than a threshold.

- The lowest and the highest prices for the collected bottles and the recycled materials are respectively given by Centralized and Stackelberg games, while Nash and Centralized games respectively lead to the lowest and the highest prices for the cleaned bottles.

- The shortest and the greatest demands for the cleaned bottles are respectively obtained from Centralized and Stackelberg games and this inference is reversed for the demand of the recycled materials.

- From the collector's and cleaner's point of view, it is more beneficial to establish Centralized game among the members, if a threshold is met. Moreover, the highest profits received by the recycler and whole system are given under Centralized game.

- From the whole system's point of view, it is beneficial to clean the collected bottles through a cleaner by giving a share of the profit to him. follows:

Finally, a sensitivity analysis is done on the considered parameters. The inferences are summarized as

- $\quad$ More negotiation powers give higher profits for the members.

- Higher the self-price/cross-price sensitivity of the suppliers' demands gives lower/higher profits to the members and whole system.

- Strategies that decrease the self-price and increase the cross-price sensitivities of the suppliers' demands make the environment friendlier.

There are some possible directions for future researches. To coordinate the members, various contracts can be investigated on the considered research problem. In this paper, the suppliers' demands were obtained based on the prices. Other types of the demand functions can be considered in future studies. Moreover, the gametheoretic models were established under a deterministic scenario. One can investigate the disruption concepts under the considered supply chain applying the stochastic models.

\section{Declarations}

\subsection{Funding}

This research did not receive any specific grant from funding agencies in the public, commercial, or not-forprofit sectors.

\subsection{Conflicts of interest}

The authors declare that they have no known competing financial interests or personal relationships that could have appeared to influence the work reported in this paper.

\subsection{Availability of data and material}

Not applicable

\subsection{Code availability}

Not applicable

\section{Appendix A. Proofs and notations}

Supplementary materials associated with the proofs of theorems and the defined notations can be found in the online version at .... 


\section{References}

Akbar A, Liew K (2020) Assessing recycling potential of carbon fiber reinforced plastic waste in production of eco-efficient cement-based materials. Journal of Cleaner Production 274:123001

Caetano JA, Schalch V, Pablos JM (2020) Characterization and recycling of the fine fraction of automotive shredder residue (ASR) for concrete paving blocks production. Clean Technologies and Environmental Policy 22:835-847

Casadesus-Masanell R, Crooke M, Reinhardt F, Vasishth V (2009) Households' willingness to pay for "green" goods: evidence from Patagonia's introduction of organic cotton sportswear. Journal of Economics \& Management Strategy 18:203-233

Chen W, Hu Z (2018) Using evolutionary game theory to study governments and manufacturers' behavioral strategies under various carbon taxes and subsidies. Journal of Cleaner Production 201:123-141

Chen YJ, Sheu J-B (2009) Environmental-regulation pricing strategies for green supply chain management Transportation Research Part E: Logistics and Transportation Review 45:667-677

Doan HN, Vo PP, Hayashi K, Kinashi K, Sakai W, Tsutsumi N (2020) Recycled PET as a PDMSFunctionalized electrospun fibrous membrane for oil-water separation. Journal of Environmental Chemical Engineering 8:103921

Eneh OC (2021) Green chemistry models for municipal electronic waste treatment for resource recovery, repair, recycling and reuse in Nigeria. Clean Technologies and Environmental Policy:1-10

Feng L, Govindan K, Li C (2017) Strategic planning: Design and coordination for dual-recycling channel reverse supply chain considering consumer behavior. European Journal of Operational Research 260:601612

Fu XY, Zhu QH, Dou Y (2012) Evolutionary game analysis of recycling channel of reverse supply chain under collection competition. Operations Research and Management Science 4:41-51

Gautam A, Kumar S (2005) Strategic planning of recycling options by multi-objective programming in a GIS environment. Clean Technologies and Environmental Policy 7:306-316

Goli VSNS, Mohammad A, Singh DN (2020) Application of municipal plastic waste as a manmade neoconstruction material: issues \& wayforward. Resources, Conservation and Recycling 161:105008

Gopinath KP, Nagarajan VM, Krishnan A, Malolan R (2020) A Critical Review on Energy, Environmental and Economic Factors on Various Processes Used to Handle and Recycle Plastic Wastes: Development of a comprehensive Index. Journal of Cleaner Production:123031

Grimes-Casey HG, Seager TP, Theis TL, Powers S (2007) A game theory framework for cooperative management of refillable and disposable bottle lifecycles. Journal of Cleaner Production 15:1618-1627

He L, Yuan H (2020) Investigation of construction waste recycling decisions by considering consumers' quality perceptions. Journal of Cleaner Production 259:120928

Huang M, Song M, Lee LH, Ching WK (2013) Analysis for strategy of closed-loop supply chain with dual recycling channel. International Journal of Production Economics 144:510-520

Jacobs BW, Subramanian R (2012) Sharing responsibility for product recovery across the supply chain. Production and Operations Management 21:85-100

Jafari H, Hejazi SR, Rasti-Barzoki M (2016) Sustainable development by waste recycling under a three-echelon supply chain: A game-theoretic approach. Journal of Cleaner Production 142:2252-2261

Ji P, Ma X, Li G (2015) Developing green purchasing relationships for the manufacturing industry: An evolutionary game theory perspective. International Journal of Production Economics 166:155-162

Jin Y, Tang Z, Zhou Q, Zeng H, Mo S (2020) A government value compensation model of waste recycling in an industrial park: A game theory approach. Journal of Cleaner Production 275:122976

Kaushal RK, Nema AK (2012) An analysis of preferences for hazardous substances free products: manufacturing, use and end of life of mobile phones. Waste Management \& Research:0734242X12454697

Kaushal RK, Nema AK (2013) Multi-stakeholder decision analysis and comparative risk assessment for reuserecycle oriented e-waste management strategies: a game theoretic approach. Waste Management \& Research 31:881-895

Kaushal RK, Nema AK, Chaudhary J (2015) Strategic exploration of battery waste management: A gametheoretic approach. Waste Management \& Research:0734242X15587932

Kreiger M, Anzalone GC, Mulder ML, Glover A, Pearce JM (2012) Distributed recycling of post-consumer plastic waste in rural areas. MRS Online Proceedings Library 1492:101-106

Krikke H, Bloemhof-Ruwaard J, Van Wassenhove L (2003) Concurrent product and closed-loop supply chain design with an application to refrigerators. International Journal of Production Research 41:3689-3719

Kumar A, Prakash G, Kumar G (2020) Does environmentally responsible purchase intention matter for consumers? A predictive sustainable model developed through an empirical study. Journal of Retailing and Consumer Services 58:102270 
Leonas KK (2017) The use of recycled fibers in fashion and home products. Textiles and Clothing Sustainability:55-77

Long H, Liu H, Li X, Chen L (2020) An Evolutionary Game Theory Study for Construction and Demolition Waste Recycling Considering Green Development Performance under the Chinese Government's RewardPenalty Mechanism. International Journal of Environmental Research and Public Health 17:6303

Lou HH, Kulkarni M, Singh A, Huang YL (2004) A game theory based approach for emergy analysis of industrial ecosystem under uncertainty. Clean Technologies and Environmental Policy 6:156-161

Lu L, Qi X, Liu Z (2014) On the cooperation of recycling operations. European Journal of Operational Research 233:349-358

Ma L, Zhang L (2020) Evolutionary game analysis of construction waste recycling management in China. Resources, Conservation and Recycling 161:104863

Majumdar A, Shukla S, Singh AA, Arora S (2020) Circular fashion: Properties of fabrics made from mechanically recycled poly-ethylene terephthalate (PET) bottles. Resources, Conservation and Recycling 161:104915

Menges R, Cloos J, Greiff M, Wehrle J, Goldmann D, Rabe L (2021) Recycling behavior of private households: an empirical investigation of individual preferences in a club good experiment. Clean Technologies and Environmental Policy 23:843-856

Minakova I, Bukreeva BT, Timofeeva O (2018) Improvement of solid waste management: organizational and technological aspects. Journal of Applied Engineering Science 16:99-103

Mohanraj C, Senthilkumar T, Chandrasekar M (2017) A review on conversion techniques of liquid fuel from waste plastic materials. International Journal of Energy Research 41:1534-1552

Nash J (1950) The bargaining problem Econometrica. Journal of the Econometric Society 18:155-162

Qiu R-z, Huang X (2007) Coordination model for closed-loop supply chain with product recycling. JournalNortheastern University Natural Science 28:883

Rausch TM, Kopplin CS (2020) Bridge the gap: Consumers' purchase intention and behavior regarding sustainable clothing. Journal of Cleaner Production 278:123882

Ros-Chumillas M, Belissario Y, Iguaz A, López A (2007) Quality and shelf life of orange juice aseptically packaged in PET bottles. Journal of Food Engineering 79:234-242

Shen H, Peng Y, Guo C (2018) Analysis of the evolution game of construction and demolition waste recycling behavior based on prospect theory under environmental regulation. International journal of environmental research and public health $15: 1518$

Sheu J-B (2011) Bargaining framework for competitive green supply chains under governmental financial intervention. Transportation Research Part E: Logistics and Transportation Review 47:573-592

Sheu J-B, Chen YJ (2012) Impact of government financial intervention on competition among green supply chains. International Journal of Production Economics 138:201-213

Shirvanimoghaddam K, Motamed B, Ramakrishna S, Naebe M (2020) Death by waste: Fashion and textile circular economy case. Science of The Total Environment 718:137317

Soltani A, Sadiq R, Hewage K (2016) Selecting sustainable waste-to-energy technologies for municipal solid waste treatment: a game theory approach for group decision-making. Journal of Cleaner Production 113:388-399

Su Y (2020) Multi-agent evolutionary game in the recycling utilization of construction waste. Science of The Total Environment 738:139826

Van Caneghem J, Van Acker K, De Greef J, Wauters G, Vandecasteele C (2019) Waste-to-energy is compatible and complementary with recycling in the circular economy. Clean Technologies and Environmental Policy 21:925-939

Xu L, Shi J, Chen J (2020) Pricing and collection rate for remanufacturing industry considering capacity constraint in recycling channels. Journal of Complexity: 2020

Yi Y, Liang J (2014) Hybrid recycling modes for closed-loop supply chain under premium and penalty mechanism. Computer Integrated Manufacturing Systems 20:215-223

Yu Z, Tianshan M, Rehman SA, Sharif A, Janjua L (2020) Evolutionary game of end-of-life vehicle recycling groups under government regulation. Clean Technologies and Environmental Policy:1-12

Zgheib N, Takache H (2021) Recycling of used lubricating oil by solvent extraction: Experimental results, Aspen Plus simulation and feasibility study. Clean Technologies and Environmental Policy 23:65-76

Zhou X, Zhao R, Cheng L, Min X (2019) Impact of policy incentives on electric vehicles development: a system dynamics-based evolutionary game theoretical analysis. Clean Technologies and Environmental Policy 21:1039-1053 


\section{Supplementary Files}

This is a list of supplementary files associated with this preprint. Click to download.

- GrapghicalAbstract.docx

- OnlineMaterialAppendixA.docx 